\title{
Pulmonary Empyema and Mediastinal Abscess Resulting from Esophageal Carcinoma
}

Key words: pulmonary empyema, mediastinal abscess, esophageal carcinoma
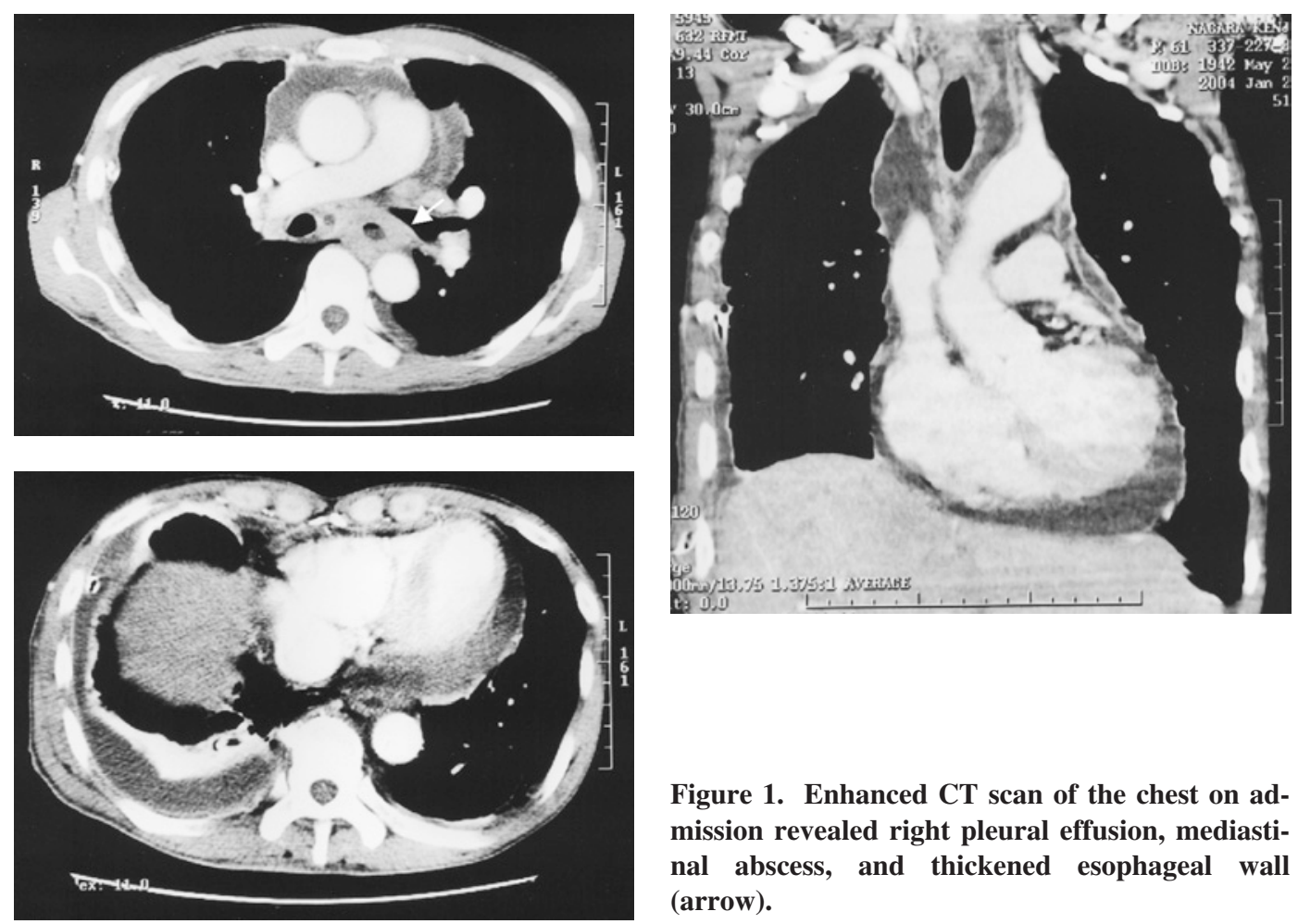

Figure 1. Enhanced CT scan of the chest on admission revealed right pleural effusion, mediastinal abscess, and thickened esophageal wall (arrow).

A 61-year-old male was admitted to the hospital with dyspnea and chest pain. Vital signs were blood pressure, 90/60 $\mathrm{mmHg}$ and temperature, $36.6^{\circ} \mathrm{C}$. Remarkable findings of physical examination included decreased breath sounds on the right side of his chest and basilar coarse crackles. A chest X-ray film obtained on admission showed a massive right-sided pleural effusion. Examination of an aspirate led us to the diagnosis of pulmonary empyema. A CT scan of the chest revealed a mediastinal abscess (Fig. 1) and a thickening of esophageal wall, suggesting the presence of esophageal carcinoma. Gastroesophageal endoscopy revealed a stenosis of lower esophageal area due to esophageal carcinoma detected by pathological examination. Although esophageal carcinoma is sometimes accompanied by esophageal perforation as a lifethreatening problem, pulmonary empyema and mediastinal abscess are relatively rare. This case suggests that esophageal carcinoma must be carefully ruled out as one of the contributory factors of empyema and mediastinal abscess.

Mitsutoshi Hayashi, Ayako KIMURA, Isao YAMAWAKI and Shin-ichiro OHKAWA From the Department of Internal Medicine, Tokyo Women's Medical University Daini Hospital, Tokyo Received for publication January 7, 2005; Accepted for publication February 23, 2005

Reprint requests should be addressed to Dr. Mitsutoshi Hayashi, the Department of Internal Medicine, Tokyo Women's Medical University Daini Hospital, 2-1-10 Nishiogu, Arakawa-ku, Tokyo 110-8567 